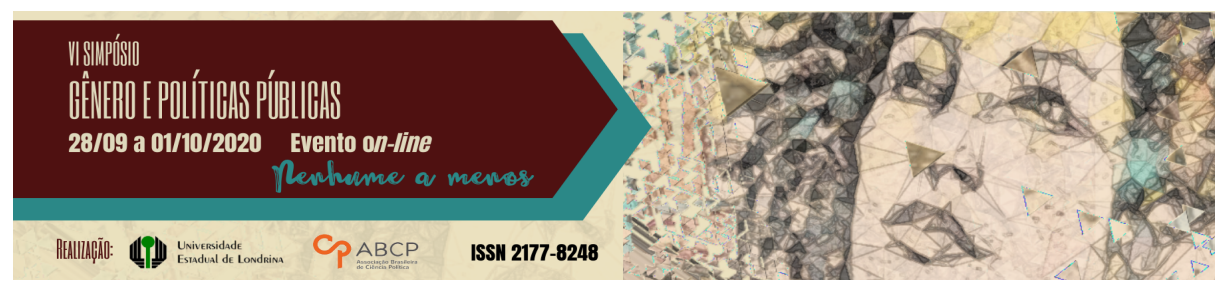

\title{
Visões de Estado sobre as mulheres: avanços e desafios das políticas públicas para o mercado de trabalho
}

\author{
Erica da Cruz Novaes Gonçalves Dias ${ }^{1}$
}

\section{Resumo}

As políticas públicas voltadas para a inserção, manutenção e atuação das mulheres no mercado de trabalho passaram por significativas transformações nas últimas décadas. O Estado, enquanto agente principal deste processo, implantou ações distintas, voltadas à proteção, à instauração de normas trabalhistas e previdenciárias, qualificação e incentivo de práticas de equidade no ambiente de trabalho. O presente trabalho pretende discutir sobre as fases iniciais do Programa Pró-Equidade de Gênero e Raça enquanto política voltada às mulheres no campo do trabalho. Para tanto, discorremos sobre os contextos que influenciaram no surgimento desta ação, o papel da secretaria de Políticas para as Mulheres e as articulações por ela realizadas. Identificamos as fragilidades do processo democrático no país como limitantes à continuidade do Programa e a urgência de se pensar em novos modelos de atuação de entidades representativas das demandas das mulheres, diante das transformações correntes no mercado de trabalho e no âmbito democrático.

Palavras-chave: trabalho; políticas públicas; mulheres.

\section{State views on women: advances and challenges of public policies for the labor market}

\section{Abstract}

Public policies aimed at the insertion, maintenance, and performance of women in the labor market have undergone significant changes in recent decades. As the main agent of this process, the State has implemented different

\footnotetext{
1 Doutoranda em Política Científica e Tecnológica na UNICAMP, ericacngdias@gmail.com
}

GT 18 - Políticas públicas de gênero no Brasil do século XXI: avanços e desafios 
actions, aimed at protection, the establishment of labor and social security rules, qualification, and encouragement of equity practices in the work environment. This paper aims to discuss the initial phases of the Gender and Race Pro- Equity Program as a policy focused on women in the field of work. For that, we discussed the contexts that influenced the emergence of this action, the role of the Secretariat for Policies for Women and the articulations carried out by it. We identified the weaknesses of the democratic process in the country as limiting the continuity of the Program and the urgency of thinking about new models of action by entities representing women's demands, given the current transformations in the labor market and in the democratic sphere.

Keywords: work; public policies; women.

\section{Introdução}

As políticas públicas voltadas para as mulheres ganharam significativa evidência no Brasil após a década de 2000, principalmente em temas como saúde, combate à violência e geração de renda. Ainda assim, alguns dados sobre determinadas políticas demonstram que muitas questões macroestruturais não foram superadas. No âmbito de políticas laborais, informações mais recentes sobre inserção das mulheres no mercado de trabalho formal, precarização da mão de obra feminina ou sobre as diferenças de renda entre homens e mulheres e brancos e negros, fica evidenciada uma repetição de antigos padrões que marcam a divisão sexual, racial e social do trabalho.

A partir disso, o presente artigo tem por objetivo discutir o processo de elaboração de políticas públicas voltadas para a atuação das mulheres no mercado de trabalho, suas limitações e as estratégias de organização e desenvolvimento de ações. Sob uma perspectiva transversal, os esforços de levantamento de informações se deram através de pesquisa documental e bibliográfica. A criação da Secretaria Especial de Políticas para as Mulheres - SPM e a principal ação por ela desenvolvido no âmbito do trabalho das mulheres: o Programa Próequidade de Gênero e Raça (PPEGR) teve nossa atenção especial neste processo.

A fim de compreender de forma ampla as ações durante a 
vigência do Programa (de 2005 a 2018) e as limitações enfrentadas nas suas etapas de formulação e implementação, foi enfatizada a relevância dos contextos político e econômico que influenciaram sua criação. Adicionalmente, a participação dos atores sociais nas etapas de conformação de conteúdo do programa foi considerada a partir dos contextos de influência, através do mapeamento dos documentos oficiais.

Com este trabalho, pretende-se preencher algumas lacunas no que diz respeito aos estudos sobre ações advindas do âmbito estatal, voltadas à questão de gênero e raça no mercado de trabalho e contribuir para as discussões sobre ações propositivas em contextos de limitações orçamentárias e democráticas, como os enfrentados pelo país atualmente.

\section{Atuação do Estado e as políticas laborais}

Novos contextos políticos, econômicos e de exigências para estruturas mais democráticas (DEUBEL, 2009) vêm impactando nas discussões sobre a inserção nas agendas dos Estados de considerações mais amplas no atendimento a demandas heterogêneas. Assim, os estudos sobre como se dão as políticas públicas em suas fases de formulação e implementação se tornam prementes para compreensão da distribuição de poder e das próprias funções do Estado, tendo em vista que estas representam comportamentos institucionais de diferentes grupos de interesses.

O Estado, enquanto conjunto de instituições que formaliza e coordena os mecanismos de regulação, se utiliza de ações jurídicas e administrativas e criação de estruturas organizacionais para influenciar e modificar os ambientes nos quais atua de forma central (HÖFLING, 2001). Nele, as políticas públicas representam a concretização das decisões na arena política e resultado das mobilizações de distintos atores. A compreensão deste processo de decisão envolve a identificação destes atores e dos tipos de relação de forças entre eles e o 
Estado (DEUBEL, 2009), responsável por legitimar a implementação das estratégias no jogo político.

Adicionalmente, para se compreender os critérios de elegibilidade dos programas e ações governamentais, a própria configuração histórica do trabalho no Brasil deve ser ressaltada. No país, "emprego e trabalho" consistem em um dos eixos estruturantes da ação social em âmbito federal e compõem o chamado Sistema Público de Emprego, Trabalho e Renda - SPETR (IPEA, 2006) e o Sistema Brasileiro de Proteção Social - SBPS (CARDOSO JUNIOR; JACCOUD, 2005). Esta dupla inserção reflete a necessária abrangência ampla das políticas públicas voltadas aos temas, por envolverem diferentes camadas e pautas da sociedade civil.

Porém, por muito tempo as políticas laborais foram baseadas prioritariamente nas atividades econômicas empresariais e no emprego formal, compreendendo disputas de interesses e reprodução de fatores de produção na economia (IPEA, 2020; SANTOS, 2014; MORETTO, 2010). Ficavam de lado diversos grupos sociais, principalmente os informais e os trabalhadores que não atuavam no meio urbano (CARDOSO JUNIOR; JACCOUD, 2005).

Relacionadas às transições políticas que ocorreram no país nas últimas décadas, houve uma ampliação nas ações governamentais para o emprego e renda (que incluíram esforços para atender grupos específicos como as mulheres, trabalhadores de baixa renda e escolaridade, afrodescendentes, jovens e trabalhadores domésticos), seguida pelas flexibilizações dos direitos trabalhistas ocorridas recentemente.

\section{Arena Política e as ações públicas no âmbito do trabalho}

A evolução histórica das políticas na organização de ações de amparo ao trabalhador tem na Consolidação das Leis Trabalhistas - CLT de 1943, na Constituição Federal de 1988 e na Reforma Trabalhista de 
2017 os seus marcos essenciais. Porém, entre as décadas de 1940 e o período recente, diversas outras políticas públicas foram elaboradas e implementadas no âmbito federal, inclusive com a participação de entidades coletivas e movimentos sociais. As diferenças, evoluções e complementariedade destas ações se deram em distintos momentos políticos, níveis democráticos e situação econômica nacional como panoramas para o atendimento às heterogêneas demandas.

Lançada durante o regime do Estado Novo, a CLT foi destinada à proteção da minoria de trabalhadores que atuava na indústria e comércio, embora tenha instituído políticas voltadas para o trabalho feminino de forma mais ampla, com unificação das ações existentes anteriormente e inovação no âmbito de segurança jurídica nas relações de trabalho. Com um capítulo voltado à "Proteção do Trabalho da Mulher", há foco na duração das atividades laborais, acesso ao mercado de trabalho, equidade salarial, descanso, ambiente do trabalho, dentre outros.

Durante a Ditadura, destacam-se as ações de proteção social aos trabalhadores formais, como a criação do Fundo de Garantia por Tempo de Serviço - FGTS em 1966, com o propósito de indenizar os demitidos, o SINE - Sistema Nacional de Emprego, voltado à intermediação de mão de obra, orientação e qualificação profissional (IPEA, 2006), o PIS (Programa de Integração Social) e o PASEP (Programa de Formação do Patrimônio do Servidor Público).

No processo de redemocratização do país, criou-se o Seguro Desemprego em 1986, após fases mais difíceis da crise econômica daquela década e seus impactos sobre as taxas de emprego, a fim de conceder auxílio financeiro temporário ao trabalhador demitido sem justa causa. Dois anos depois, foi criada a Constituição Federal de 1988, que visou incentivar as práticas democráticas das instituições e o aumento da participação social nas diferentes etapas de políticas, para garantir de forma coletiva a proteção, a valorização da dignidade humana e os direitos sociais em distintos campos, aplicáveis aos contratos de trabalho (DA SILVA; JACCOUD; BEGHIN, 2005; SILVA, 
2012). Ao mesmo tempo em que permitiu práticas flexibilizadoras das condições de trabalho, como a possibilidade de negociação coletiva no que concerne a salários e jornada de trabalho diferenciada (SILVA, 2012).

Nas décadas de 1980 e 2000 as alterações legislativas trataram de redimensionar algumas diretrizes de "proteção" à mulher e instauraram normas trabalhistas e previdenciárias no combate à discriminação e o impulsionamento da igualdade no mercado de trabalho. Promovidas pelo governo federal e coordenadas em sua maioria pelo Ministério do Trabalho², as novas ações incluíram programas voltados à qualificação dos trabalhadores em geral e ao fortalecimento da agricultura familiar.

A partir de 2003 houve também incentivos às ações que se inseriam no contexto de Economia Solidária, e atuações de poderes locais em projetos que incluíam apoio às incubadoras e convênios com universidades, por exemplo e atenção a grupos específicos da sociedade, como os jovens e mulheres. Posteriormente, outros estímulos como a renda mínima e ao empreendedorismo ocorreram, através da concessão de microcrédito produtivo (BRASIL, 2018).

2 O Ministério do Trabalho, Indústria e Comércio foi criado em 1930 no governo de Getúlio Vargas através do Decreto $n^{\circ} 19.433 / 1930$ e, após 89 anos, teve seu status rebaixado à secretaria pelo atual governo federal. A Secretaria do Trabalho integra agora o Ministério da Economia. 
Figura 1 - Ações federais de destaque no âmbito do trabalho, emprego e renda no Brasil de 1940 a 2017

\begin{tabular}{|c|c|c|c|c|c|c|c|c|c|c|}
\hline $\begin{array}{l}\text { Consolidação } \\
\text { das Leis } \\
\text { Trabalhistas } \\
\text { - CLT }\end{array}$ & & $\begin{array}{l}\text { Programa de } \\
\text { Integração } \\
\text { Social - PIS; } \\
\text { Programa de } \\
\text { Formação do } \\
\text { Patrimônio do } \\
\text { Servidor } \\
\text { Público - PASEP }\end{array}$ & & $\begin{array}{l}\text { Seguro } \\
\text { Desemprego }\end{array}$ & & $\begin{array}{l}\text { Plano } \\
\text { Nacional de } \\
\text { Formação } \\
\text { Profissional - } \\
\text { Planfor; } \\
\text { Programa de } \\
\text { Fortalecimento } \\
\text { da Agricultura } \\
\text { Familiar - } \\
\text { Pronaf }\end{array}$ & & $\begin{array}{l}\text { Programa } \\
\text { Pró-equidade } \\
\text { de Gênero }\end{array}$ & & $\begin{array}{l}\text { Reforma } \\
\text { Trabalhista } \\
\text { (Lei } \\
\text { 13.467/2017) }\end{array}$ \\
\hline 1943 & 1966 & 1970 & 1975 & 1986 & 1988 & 1995 & 2003 & 2005 & 2013 & 2017 \\
\hline & $\begin{array}{l}\text { Fundo de } \\
\text { Garantia por } \\
\text { Tempo de } \\
\text { Serviço- } \\
\text { FGTS }\end{array}$ & & $\begin{array}{l}\text { Sistema } \\
\text { Nacional de } \\
\text { Emprego - } \\
\text { SINE }\end{array}$ & & $\begin{array}{l}\text { Constituição } \\
\text { Federal }\end{array}$ & & $\begin{array}{l}\text { Programa } \\
\text { Primeiro } \\
\text { Emprego; } \\
\text { Economia } \\
\text { Solidária; } \\
\text { Criação da } \\
\text { Secretaria } \\
\text { Especial de } \\
\text { Políticas para } \\
\text { as Mulheres }\end{array}$ & & $\begin{array}{l}\text { Emenda } \\
\text { Constitucional } \\
\mathrm{n}^{\circ} 72 \\
\text { "PEC das } \\
\text { Domésticas" }\end{array}$ & \\
\hline
\end{tabular}

Fontes: MTE, 2015; SPM, 2006; IPEA, 2006.

Já o início da década de 2000 foi marcado pela ascensão do Partido dos Trabalhadores - PT à Presidência da República, a partir da eleição do presidente Lula em 2002. O então novo governo adotou uma postura conciliatória, desenvolveu um tom de pacificação entre os diferentes atores políticos e optou pelo não enfrentamento às macroestruturas de Estado existentes (SANTOS, 2018). Nele, algumas questões econômicas e sociais passaram por ajustes, que incluíram reformas, desregulamentações e flexibilizações das relações de trabalho por um lado. De outro, houve uma sequência de saldos positivos nas transações correntes do país por um período, uma melhora da distribuição de renda, redução do desemprego e do poder de compra e expansão do ensino superior (SANTOS, 2018).

Este ciclo político destacou-se também pela articulação governamental junto aos movimentos sociais, à burocracia sindical e aos setores intelectualizados. Diferentes organizações da sociedade civil foram envolvidas na gestão pública e, como veremos a seguir, a Secretaria Especial de Políticas para as Mulheres foi um dos resultados destas articulações e da descentralização das ações no âmbito do trabalho e renda, por inclusive promover políticas ao empoderamento 
econômico das mulheres.

Os anos finais da era PT e o biênio pós-golpe da presidente Dilma foram marcados por uma conjuntura de turbulência na política e economia do país, o que influenciou nas ações públicas voltadas ao mercado de trabalho. Em 2013 foi aprovada a "PEC das domésticas", que propôs equidade de direitos às trabalhadoras domésticas, como o direito ao FGTS, fixação jornada diária e horas extras. Por outro, houve uma intensificação da flexibilização trabalhista através da Lei 13.467/2017, que representou uma profusão de medidas que modificaram as relações trabalhistas de forma profunda em pontos elementares como jornada de trabalho, remuneração, rescisão e a permissão de novos tipos de contrato e negociações. Como afirma Carvalho (2017, p.93), na prática significou a perda do "poder de barganha dos trabalhadores".

\section{Organizações sociais e políticas para as mulheres}

As mudanças no mundo do trabalho no Brasil foram marcadas também pelas lutas históricas e participações das organizações sociais na gestão pública. Antes de adentrarmos em algumas considerações sobre este fato, enfatizamos que, como movimentos sociais, consideraremos que se constituem em:

sujeitos coletivos constituídos que se expressam por um trabalho organizativo, pela capacidade de análise, pela agenda, por estratégias, e em um espaço de debate em condições mais ou menos igualitárias (dependem da correlação de forças e da capacidade de força de cada sujeito) coordenam uma ação pontual, uma agenda comum, até uma estratégia comum de médio prazo (NOBRE; FARIA, 2003, p.623).

A fusão entre Estado e movimentos sociais ocorridos especialmente nos governos do PT não são novidade do ponto de vista de quebra de uma perspectiva de autonomia destes movimentos, tampouco de inserções deles em espaços de participação institucional. Conforme Cisne (2016), o próprio movimento feminista em âmbito 
global experimentou situações de "interferências" em sua autonomia quando do processo de sua institucionalização, relacionadas às reorganizações partidárias, às participações em espaços governamentais e à "onguização" do movimento. Federici (2019) questiona tal alinhamento com instituições como a ONU e o Banco Mundial, sob uma perspectiva crítica às articulações transversais e seus efeitos e prejuízos aos movimentos de mulheres, suas pautas, autonomia e descolamento dos movimentos de base.

Neste processo, diversos movimentos sociais alteraram suas visões sobre o Estado: de "inimigo comum" a um "espaço a ser ocupado", no qual ele não é o detentor exclusivo da gestão em âmbito público. Como afirma Mirza (2006), as ações sociais adquiriram potencialidade para influenciarem no espaço político institucional, com interseç̧ão entre as esferas dos movimentos sociais e os sistemas políticos. E os próprios movimentos passaram a valorizar de forma crescente a participação em frentes institucionais, como assembleias, audiências e conferências públicas, conselhos, dentre outros espaços (SCHERER-WARREN, 2008a).

No que diz respeito à autonomia, a partir da metade da década de 1970, os sujeitos coletivos emergentes tinham uma postura de autonomia em relação às estruturas governamentais, desempenhando pressões políticas com vistas a transformações nas estruturas (SCHERER- WARREN, 2008a). Fato que se deve principalmente à luta concomitante de suas temáticas específicas às pautas antiopressoras, diante do contexto de ditadura militar. Todavia, na história dos movimentos sociais no Brasil, o Estado foi tido como referência tanto para negociação quanto para contestação, tendo em vista a indissociação entre o social, político e o estatal como uma tendência predominante (TOURAINE, 1987; SCHERER-WARREN, 2008).

Nas décadas seguintes, a reivindicação de direitos sociais foi impulsionada pela Constituição de 1988, além da formalização de algumas entidades civis e expansão do terceiro setor no país. A relação entre alguns movimentos e o Estado se intensificou também a partir da 
participação de representantes sociais diretamente na esfera governamental, aproximação esta que causou descontentamentos em alguns movimentos contestatórios. Após 1990 percebeu-se uma internacionalização destes e uma valorização maior de suas participações em ações institucionais (SCHERER-WARREN, 2008; 2008a), ampliaram suas atividades e englobou progressivamente grupos como de mulheres homossexuais, negras, mulheres periféricas e do campo (BLAY, 2016). O que reforça, por um lado, o papel dos movimentos sociais, enquanto fontes de autocrítica das sociedades em processo de constantes transformações (HUBER, 1995), sem alterar as questões centrais de suas lutas e o desejo pela emancipação pessoal e coletiva.

Além disso, em um contexto de acirramento do regime neoliberal, as mobilizações sociais estão enfraquecidas e mais difíceis, frente a um incentivo de concorrência entre os indivíduos. Assim, evidencia-se a importância do debate sobre projetos emancipatórios de justiça social e da superação dos obstáculos por vezes institucionalizados que limitam ou impedem determinados sujeitos de se reconhecerem (DARDOT; LAVAL, 2016) ou de terem suas demandas incluídas nas discussões para a formulação de políticas públicas.

Adicionalmente, Matos (2010) indica que a fase mais recente do movimento de mulheres no Brasil apresenta um processo de institucionalização de suas demandas, marcado pela elaboração, implementação e monitoramento de políticas públicas. Atrelado a isto, haveria um esforço para criação de mecanismos de coordenação destas políticas nas esferas federal, estadual e municipal, além da criação de organizações não-governamentais (ONGs), redes e fóruns de discussões e comunicações com vistas a ampliar e estender a agenda feminista.

\section{A SPM e a institucionalização das lutas das feministas no Brasil}

O conjunto daquelas características que compõe as histórias dos movimentos de mulheres no período recente ilustra as complexidades 
das transformações políticas e de representatividade, assim como na inclusão de distintas demandas no âmbito das políticas públicas. O caminho para a institucionalização destes movimentos no Brasil teve como marco a criação da Secretaria Especial de Políticas para as Mulheres (SPM) em 2003, cujas atribuições incluíam a assessoria à Presidência, elaboração de planejamento de gênero nas diferentes esferas governamentais e promoção da implementação de legislação afirmativa.

O status de ministério dada à SPM aumentava sua influência na gestão federal, com aporte administrativo significativo e inserção de suas pautas em ministérios e na própria presidência (BOHN, 2010), bem como um fortalecimento de organismos institucionais para a igualdade de gênero (SPM, 2005). Neste sentido, a criação da Secretaria incorporou o histórico Conselho Nacional dos Direitos da Mulher (CNDM), ao qual foi dada a responsabilidade de dar suporte à SPM em suas articulações governamentais e com a sociedade civil.

Das ações promovidas pela SPM, destacam-se as relativas ao enfrentamento da violência contra as mulheres, à transversalidade de gênero e as de financiamento de projetos de convênio entre a instituição e distintas entidades para a formação e inserção das mulheres no mercado de trabalho (CARVALHO, 2018). Especificamente em relação ao último tópico, foram criadas frentes de ação de alcance nacional para a promoção de equidade nas relações de trabalho, com aportes financeiros crescentes no período ${ }^{3}$, seguindo tendência do orçamento geral destinado à Secretaria.

A evolução dos recursos financeiros da SPM se alinhava à expansão das demandas por ela atendidas, advindas de seu caráter participativo, no qual diferentes segmentos tiveram seus apontamentos considerados nas formulações de políticas públicas (BOHN, 2010), em um modelo híbrido, que combinava "características parcialmente

\footnotetext{
${ }^{3}$ Em 2004, a despesa orçamentária prevista para a SPM estava em R \$ 26,1 milhões, valor que chegou a $\mathrm{R} \$ 260,3$ milhões em 2015 (SIGA BRASIL, 2020).
} 
burocráticas com participativas" (RODRIGUEZ GUSTÁ; MADERA; CAMINOTTI; 2017, p. 455). Para tanto, a entidade apoiou a realização das Conferências Nacionais de Políticas para as Mulheres (CNPM), que reuniu em suas quatro edições representantes da sociedade civil nas discussões sobre ações e prioridades inseridas nos Planos Nacionais de Políticas para as Mulheres (PNPM).

O trabalho das mulheres foi incluído nas ações estruturantes dos três PNPMs, nos quais à autonomia econômica foram atreladas a igualdade no mundo do trabalho, inclusão social e equidade. Estes propósitos integraram os esforços a serem empreendidos no campo do trabalho para as mulheres nos anos que se seguiram e serviram como parâmetro para a inserção na Agenda governamental de políticas como o Programa Pró-equidade de Gênero e Raça.

\section{Programa Pró-Equidade de Gênero e Raça}

O trabalho, como foco privilegiado de incidência de políticas públicas torna- se sinônimo de inclusão social, autonomia e desenvolvimento. Considerado em um marco amplo, o trabalho precisa cumprir, para além da sua função produtiva, a tarefa de representar um meio de expressão dos sujeitos e, ao mesmo tempo, um elo social fortalecido (BRASIL, 2013).

Tais considerações da ex-ministra da SPM Eleonora Menicucci ilustra a importância que o Programa Pró-Equidade de Gênero representa à ampliação de perspectivas na formulação e implementação de políticas públicas para o trabalho das mulheres em um contexto de Conferências Nacionais, de Planos Nacionais, com articulações junto a movimentos sociais e transversalização das pautas. $O$ "ir além" da função produtiva, implicou no desafio à SPM de desenvolver políticas para o trabalho das mulheres que pudessem considerar questões reconhecidas como limitantes à sua atuação, autonomia econômica, sua inclusão no mercado de trabalho e papel ativo para o desenvolvimento econômico do país. 
Desta maneira, em parceria com a Organização das Nações Unidas - ONU e a Organização Internacional do Trabalho - OIT, foi criado o Programa Pró-Equidade de Gênero em 2005, cujos objetivos foram assim delineados:

Contribuir para a eliminação de todas as formas de discriminação no acesso, remuneração, ascensão e permanência no emprego; Conscientizar e sensibilizar empregadoras/es e estimular as práticas de gestão que promovam a igualdade de oportunidades entre homens e mulheres dentro das empresas; Reconhecer publicamente o compromisso das empresas com a eqüidade de gênero no mundo do trabalho; Criar a rede Pró-Eqüidade de Gênero; Construir um banco de "boas práticas" de gestão que promovam a eqüidade de gênero no mundo do trabalho (BRASIL, 2005).

Estas cinco frentes de ação determinadas pelo Programa evidenciaram o seu alcance: com atuação direta junto às empresas e sua gestão, através de incentivo de mudança de cultura organizacional e na gestão de pessoas. Pretendia-se promover esforços nas etapas de recrutamento e seleção, no treinamento de funcionários, em planos de carreira, benefícios e remuneração, em segurança do trabalho, no combate às diferentes formas de discriminação e assédio, equidade de gênero em todas as esferas das empresas e nas comunicações junto aos funcionários e parceiros de negócios (idem).

O foco inicial foram as empresas públicas de grande porte, que solicitavam adesão voluntária a cada edição. Para tanto, preenchiam e enviavam um termo disponibilizado no site da SPM e, posteriormente, um termo de compromisso, no qual se comprometiam a realizarem as ações planejadas. Para o desenvolvimento destas, as organizações participantes contavam com o suporte técnico gratuito de um Comitê composto por especialistas, que assessorava a coordenação dessa política pública. Desta maneira, as empresas recebiam significativo auxílio para o cumprimento das ações planejadas e eram avaliadas após um ano. Caso conseguissem cumprir ao menos 70\% do planejamento, 
recebiam um reconhecimento chamado de "Selo Pró-Equidade de Gênero".

Grandes empresas públicas como Petrobras, Itaipu e Banco do Brasil participaram do Programa, que a partir da $4^{\mathrm{a}}$ edição possibilitou a inclusão de representantes do setor privado. Foi nesta edição igualmente que a questão da dimensão "raça" foi inserida explicitamente na pauta e na nomenclatura da política pública, na data simbólica de 13 de maio de 2011, através de Portaria n.43. O texto desta Portaria aponta que a nova caracterização do Programa estava de acordo tanto com as recomendações das Conferências Nacionais, quanto dos Planos Nacionais de Políticas e ao Plano Plurianual do Governo Federal, referente ao período de 2008 a 2011 e detalha com refinamento as características e pressupostos do Programa.

Ao todo, o PPEGR teve seis edições, contou com a participação de mais de uma centena de empresas e se estendeu até o final do mandato da presidente Dilma. Durante o governo Temer, a sexta edição foi congelada na fase de avaliação das ações adotadas pelas participantes. Com o novo governo de 2019, este congelamento ganhou o status de "em avaliação" e assim continuou até o presente momento, não sendo, portanto, finalizado formalmente.

\section{Discussões iniciais}

Em sua evolução histórica, as políticas para o mercado de trabalho por vezes consideraram as participações das mulheres de forma limitada, com aspectos de cunho protetor, voltadas ao trabalho formal e pautando questões como trabalho noturno, gravidez, proibição de atuação em ambientes insalubres, dentre outros. Tal tendência foi reduzida parcialmente em algumas ações públicas, marcadas por uma maior participação da sociedade civil em suas fases de formulação e implementação.

Em relação às políticas públicas de trabalho para as mulheres, as 
mudanças nos contextos político e econômico a partir da década de 2000 foram essenciais para o avanço nas pautas das discussões e ampliação de representatividade institucional. O novo governo do Partido dos Trabalhadores estimulou uma estrutura institucional mais democrática, no sentido de permitir a criação de entidades como a Secretaria de Políticas para as Mulheres - SPM, com foco em grupos sociais mais vulneráveis às transformações correntes. Se, por um lado as críticas a esta estrutura apontavam para uma dependência governamental, passível de limitação de críticas, por outro lado, a SPM representou igualmente uma ampliação da participação estatal e não-estatal na formulação de políticas para o emprego, trabalho e renda.

A atuação estatal na formulação de tais políticas se deu a partir da articulação da Secretaria em diferentes ministérios e outras entidades governamentais, com uma capacidade de destaque para inserção da pauta gênero e raça nas discussões. Para tal, o seu status de ministério e a consequente estrutura administrativo-financeira foram fundamentais. Ao mesmo tempo, a SPM articulou grandes Conferências Nacionais para, a partir das discussões com diferentes camadas da sociedade civil, elencar as pautas a serem inseridas em sua agenda governamental. Os resultados deste processo foram vários, mas no campo do trabalho, o Programa Pró-equidade de Gênero e Raça se destacou por diversos motivos.

O primeiro diz respeito ao seu ineditismo enquanto política pública de amplitude nacional voltado à promoção de equidade nas empresas públicas, em um momento no qual termos como "diversidade" e "equidade" estavam sendo aprofundados nas estruturas gerenciais das grandes companhias transnacionais. Ainda que o marcador "Raça" tenha sido inserido no Programa apenas em sua quarta edição, este aspecto evidenciou um caráter político- ideológico da ação pública enquanto uma política que não visava a neutralidade, mas que enfatizava diretamente a necessidade de se agir diante de opressões estruturais, no caso, a discriminação por gênero e o racismo nos espaços de execução das atividades econômicas realizadas pelas 
mulheres.

Outro elemento refere-se à aproximação da entidade com grupos sociais, especialmente os movimentos de mulheres, os quais possuíam comunicação direta com a Secretaria, através do Conselho Nacional dos Direitos da Mulher, responsável pelas intermediações entre as partes. Este caráter híbrido da entidade foi refletido na estrutura formulada para o Programa Pró- equidade de Gênero e Raça, o qual incluía a participação mútua do Estado e das empresas participantes. Cabia aos Comitês-técnicos do Programa o auxílio para implementação, desenvolvimento e a avaliação das ações realizadas pelas empresas, enquanto às empresas competia a elaboração e execução dos planos que pretendiam eliminar as discriminações em seu ambiente interno e nas relações com seus parceiros de negócio.

O trabalho das mulheres foi inserido na formulação do Programa como um sinônimo de inclusão social, de autonomia e meio para que elas pudessem participar do desenvolvimento econômico do país de maneira ampla e democrática. Tais aspectos reforçam a configuração transversal que baseou as discussões desta política pública, indo além das que historicamente vinham sendo implementadas para as mulheres, podendo ser caracterizada como uma política pública "de mercado" e complementar (MORETTO, 2007; OFFE, 1995) às políticas adotadas pelos Governos do PT. Todavia, é importante discorrer sobre as limitações de tais ações diante das transformações no mercado de trabalho das últimas décadas, principalmente por terem sido voltadas às mulheres no mercado formal e às empresas de grande e médio porte. Considerando que a maior parte das empresas no país são de pequeno porte e diante dos crescentes níveis de informalidade no mercado de trabalho que abarcam muitas mulheres, a implementação do Programa não foi passível de alcançar uma significativa parcela das mulheres economicamente ativas.

No mais, enquanto política pública, o PPEGR foi formulado e implementado sob um viés de cooperação múltipla interna e externa ao país, sendo esta última desenvolvida junto à OIT e à ONU. Este fato 
corrobora às discussões sobre a institucionalização das pautas dos movimentos de mulheres, cujas extensões globais por um lado evidenciam a ampliação do debate sobre gênero e raça e, por outro, questiona sobre as possíveis adequações das pautas feministas àquelas e às outras instituições, como as empresas participantes do Programa Pró- Equidade de Gênero e Raça. Apontamentos semelhantes são importantes para se pensar nas articulações necessárias para formulação e implementação de políticas baseadas em marcadores como gênero e raça e as limitações decorrentes das diversificações dos atores ou das legitimações às quais estas pautas podem estar expostas.

Por fim, embora o Programa Pró-equidade de Gênero e Raça tenha sido resultado de esforços em rede de distintos atores e de um processo de institucionalização das pautas dos movimentos de mulheres, sua fragilidade diante das alterações democráticas e governamentais se fez evidente. Com a transição de governo Dilma para o governo Temer, a Secretaria de Políticas para as Mulheres perdeu o status que havia alcançado nos anos anteriores e, consequentemente, a estrutura administrativa, financeira e política necessárias para manter suas atividades. A ruptura do governo também representou em uma desfragmentação dentro da própria SPM e o congelamento do Programa. Fatos que foram agravados no governo seguinte.

\section{Considerações Finais}

O Programa Pró-Equidade de Gênero e Raça surgiu como uma política inédita voltada ao atendimento de demandas heterogêneas dos movimentos sociais para a inserção e manutenção das mulheres no mercado de trabalho formal. Sob a coordenação da SPM, esta ação pública foi conduzida de forma democrática e apresentou um interesse significativo de participação de empresas no desenvolvimento de práticas de eliminação de discriminações em suas estruturas produtivas e administrativas. A novidade desta ação conjunta entre Estado e empresas contra questões macroestruturais dadas foi resultado de uma 
atuação ampla da SPM, uma instituição criada igualmente a partir de um inédito status de ministério voltado aos direitos das mulheres.

A gestão pública e suas articulações com o empresariado e sociedade civil se viu, por outro lado, limitada às transições de governo, após a ruptura democrática de 2016. Um ponto importante a ser enfatizado neste momento no qual o novo governo de direita, instituído em 2019, explicitamente se posiciona contra políticas progressistas e movimentos sociais. Logo, os avanços institucionais e políticos alcançados pelos movimentos de mulheres no Brasil sofreu um grande revés, com uma clara desarticulação das grandes estruturas desenvolvidas nos anos e gestões anteriores. Assim, a institucionalização das pautas destes movimentos na esfera pública se mostra frágil em alguns aspectos. O que evidencia a necessária rearticulação e desenvolvimento de novas alternativas de atuação dos movimentos sociais e de representatividade na esfera pública, para que as demandas das mulheres possam ser atendidas de forma prioritária.

Neste sentido, novas reivindicações de pautas também foram surgindo nos últimos anos, provocadas pelas transformações no próprio mercado de trabalho e na economia do país, agravadas pelo contexto de pandemia do COVID-19. Os avanços provocados pela SPM no âmbito de formulação e implementação de políticas públicas, através de sua grande capacidade de articulação entre diferentes atores, da esfera pública e privada, podem ser utilizados como exemplos de poder dos movimentos sociais, que acompanham tais modificações nas sociedades e que são capazes de pressionar o poder vigente em busca de atendimento daquelas modificações.

A construção de um sistema alternativo, que pretenda incluir as mulheres que vivem às margens das sociedades representa não apenas um desafio político, econômico e de saúde pública neste momento, mas uma nova perspectiva temporal, na qual é premente a urgência das práticas e discussões que possam fazer frente às hierarquias historicamente dadas para as mulheres na sociedade e seus enfrentamentos às divisões e à precarização do trabalho. Se nas últimas 
décadas a atuação junto ao Estado se deu a partir de modelos mais progressistas de governo, há de se discutir no momento presente novos caminhos de atuação diante de um cenário mais restritivo e opressor. E, neste ponto, a história de lutas e conquistas dos movimentos de mulheres podem representar um guia de encorajamento na busca por estratégias e desenvolvimento novas redes articuladas de ações.

\section{Referências}

AGUM, R.; RISCADO, P.; MENEZES, M. Políticas Públicas: conceitos e análise em revisão. Revista Agenda Politica, v. 3, n. 2, jul./dez. 2015.

ALVAREZ, S.; MATOS, M. Apresentação. In: Quem são as mulheres das politicas para as mulheres no Brasil: o feminismo estatal participativo brasileiro. Porto Alegre, RS: Zouk, 2018.

BLAY, E. A. Como as mulheres se construíram como agentes políticas e democráticas: o caso brasileiro. In: AVELAR, Lucia. BLAY, Eva Alterman (Org.). 50 Anos de Feminismo Argentina, Brasil. São Paulo: Edusp, 2016.

BOHN, S. Feminismo Estatal sob a Presidência Lula: o caso da Secretaria de Políticas para as Mulheres. Revista Debates, Porto Alegre, v. 4, n. 2, p. 81-106, jul./dez. 2010.

BRASIL. Presidência da República. Secretaria de Políticas para Mulheres. Práticas de igualdade: ações de destaque na $4^{\text {a }}$ edição. Brasília: SPM, 2013.

BRASIL. Presidência da República. Secretaria Especial de Políticas para as Mulheres. Plano Nacional de Políticas para as Mulheres. Brasília: 2006.

BRASIL. Presidência da República. Secretaria Especial de Políticas para as Mulheres. Portaria n. 43 de 13.05.2011. Brasília, 2011.

CARDOSO JR., J. C.; JACCOUD, L. Políticas sociais no Brasil: organização, abrangência e tensões da ação estatal. IPEA: 2009.

CARDOSO JR., J. C.; JACCOUD, L. Questão social e políticas sociais no Brasil contemporâneo. In: JACCOUD, Luciana (Org.). Questão social e políticas sociais no Brasil contemporâneo. Brasília: IPEA, 2005. 
CARVALHO, L. P. A SPM e as políticas para as mulheres no Brasil: saltos e sobressaltos em uma institucionalização das demandas das agendas feministas. In: MATOS, M.; ALVAREZ, S. S. (Org.). Quem são as mulheres das politicas para as mulheres no Brasil: o feminismo estatal participativo brasileiro. Porto Alegre: Zouk, 2018.

CARVALHO, S. S de. Uma visão geral sobre a Reforma Trabalhista. 2017. Disponível em: < http://repositorio.ipea.gov.br/handle/11058/8116>. Aceso em: 20 jul. 2020.

CISNE, M. Feminismo e consciência de classe no Brasil. São Paulo: Cortez, 2014.

DA SILVA, F. B.; JACCOUD, L.; BEGHIN, N. Políticas Sociais no Brasil: Participação Social, Conselhos e Parceria. In: JACOUD, L. (Org.). Questão social e políticas sociais no Brasil contemporâneo. Brasília: IPEA, 2005.

DARDOT, P.; LAVAL, C. A nova razão do mundo: ensaio sobre a sociedade neoliberal. São Paulo: Boitempo, 2016.

DEUBEL, A. N. R. Políticas Públicas: Formulación, Implementación y Evaluación. Bogotá: Ediciones Aurora, 2009.

FEDERICI, S. O ponto zero da revolução: trabalho doméstico, reprodução e luta feminista. Tradução de Coletivo Sycorax. São Paulo: Editora Elefante, 2019.

HÖFLING, E. de M. Estado e políticas (públicas) sociais. Cadernos Cedes, ano XXI, n. 55, nov. 2001.

HUBER, J. Movimentos Sociais. Plural, Sociologia, USP, n. 2, p. 132-150, 1995.

IBGE. Estatísticas de Gênero: indicadores sociais das mulheres no Brasil. Rio de Janeiro: IBGE, 2018.

IPEA. Brasil: o estado de uma nação - mercado de trabalho, emprego e informalidade. Rio de Janeiro: IPEA, 2006.

IPEA. O paradigma de Sistema Público de Emprego da OIT e a sua construção histórica no Brasil. Texto para discussão 2562. Instituto de Pesquisa Econômica Aplicada. Brasília-Rio de Janeiro: IPEA, 2020. 
MIRZA, C. Movimientos sociales y sistemas políticos em América Latina: la construción de nuevas democracias. Buenos Aires: CLACSO, 2006.

MORETTO, A. J. O Sistema público de emprego no Brasil: uma construção inacabada. 2007. Tese (Doutorado em Economia) - Instituto de Economia, Universidade Estadual de Campinas-Unicamp, Campinas, 2007.

MORETTO, A. J. Políticas de emprego e sua contribuição à redução da informalidade e discriminação no mercado de trabalho brasileiro: a experiência recente. Escritório da OIT no Brasil. Brasília: OIT, 2010.

NOBRE, M.; FARIA, N. Feminismo em movimento: temas e processos organizativos da Marcha Mundial das Mulheres no Fórum Social Mundial. Estudos Feministas, Florianópolis, v. 11, n. 2, p. 623-632, jul./dez. 2003.

RODRÍGUEZ GUSTÁ, A. L.; MADERA, N.; CAMINOTTI, M. Governance Models of Gender Policy Machineries under Left and Right Governments in Latin America. Social Politics: International Studies in Gender, State and Society, n. 24, v. 4, p. 452-480, 2017.

SANTOS, F. L. B. Uma história da onda progressistas sul-americana (19982016). São Paulo: Elefante, 2018.

SCHERER-WARREN, I. Movimentos Sociais no Brasil Contemporâneo. História: Debates e Tendência, v. 7, n. 1, p.9-21, 2008a.

SCHERER-WARREN, I. Redes de Movimentos Sociais na América Latina: Caminhos para uma Política Emancipatória. Caderno $\mathrm{CRH}$, Salvador, v. 21, n. 54, p. 505-517, set./dez. 2008.

SILVA, C. C. M. A Proteção ao Trabalho na Constituição Federal de 1988 e a adoção do Permissivo Flexibilizante da Legislação Trabalhista no Brasil. Constituição, Economia e Desenvolvimento: Revista da Academia Brasileira de Direito Constitucional, Curitiba, v. 4, n. 7, p. 274-301, jul./dez. 2012.

TOURAINE, A. Actores sociales y sistemas politicos en América Latina. Santiago: PREALC, 1987. 